\title{
QUALIDADE SANITÁRIA DE SEMENTES DE Caesalpinia ferrea: INCIDÊNCIA DE FUNGOS, CONTROLE E EFEITOS NA QUALIDADE FISIOLÓGICA COM O USO DE EXTRATOS VEGETAIS
}

\author{
José George Ferreira de Medeiros ${ }^{1}$, Aderson Costa Araújo Neto ${ }^{2}$, Edcarlos Camilo da Silva ${ }^{3}$, \\ Min-Fu Nascimento Huang ${ }^{4}$, Luciana Cordeiro do Nascimento ${ }^{5}$ \\ ${ }^{1}$ Universidade Federal da Paraíba, Programa de Pós-Graduação em Agronomia, Areia, Paraíba, Brasil - \\ georgemedeiros_jp@ hotmail.com \\ ${ }^{2}$ Universidade Estadual do Sudoeste da Bahia, Programa de Pós-Graduação em Agronomia, Vitória da Conquista, Bahia, Brasil - \\ aderson_biologo@hotmail.com \\ ${ }^{3}$ Universidade Federal da Paraíba, Curso de Agronomia, Areia, Paraíba, Brasil - edcarloscamilo@bol.com.br \\ ${ }^{4}$ Universidade Federal da Paraíba, Programa de Pós-Graduação em Química, João Pessoa, Paraíba, Brasil - www.min- \\ fu@ hotmail.com \\ ${ }^{3}$ Universidade Federal da Paraíba, Departamento de Fitotecnia e Ciências Ambientais, Areia, Paraíba, Brasil - \\ luciana.cordeiro@cca.ufpb.br
}

Recebido para publicação: 25/10/2013 - Aceito para publicação: 09/06/2014

\begin{abstract}
Resumo
As sementes são eficientes meios de disseminação e transmissão de patógenos e, frequentemente, introduzem novos focos de infecção em áreas isentas. A utilização de extratos de plantas com propriedades antimicrobianas são alternativas ecológicas e promissoras para substituir a proteção promovida pela aplicação de fungicidas. Assim, objetivou-se avaliar o efeito dos extratos de alamanda (Allamanda blanchetti L.) e melão-de-são-caetano (Momordica charantia L.) sobre a micoflora e a germinação de sementes de Caesalpinia ferrea. Para tanto, utilizaram-se lotes de sementes coletados em diferentes municípios paraibanos (Areia, Bananeiras, Conde e Remígio), os quais foram submetidos aos testes de sanidade e de germinação. Os tratamentos fitossanitários consistiram de Testemunha; Fungicida dicarboximida (240 g.100 kg ${ }^{-1}$ ) e extratos A. blanchetti e M. charantia nas concentrações de 10, 100, 500 e 1000 ppm. Constataram-se os fungos Aspergillus flavus, A. niger, Cladosporium sp., R. stolonifer, Penicillium sp. e Nigrospora sp. nas sementes de C. ferrea. Os extratos de A. blanchetti e M. charantia nas concentrações de 500 e 1000 ppm reduziram a incidência de fungos. As maiores concentrações (500 e 1000 ppm) de ambos os extratos promoveram o aumento no percentual e na velocidade de germinação (IVG), bem como no comprimento das plântulas de $C$. ferrea.

Palavras-chave: Patologia de sementes; micoflora; controle alternativo; germinação.
\end{abstract}

\begin{abstract}
Sanitary quality of Caesalpinia ferrea seeds: incidence of fungi, control and effects on physiological quality with the use of plant extracts. Seeds are efficient to dissemination and transmission of pathogens and often introduce new foci of infection in exempted areas. The use of plant extracts with antimicrobial properties are promising and environmentally friendly alternatives to replace the protection promoted by the application of fungicides. We aimed to evaluate the effect of extracts of Allamanda blanchetti L. and Momordica charantia L. on the mycoflora and seed germination of Caesalpinia ferrea. We used lots of seeds collected in different cities of Paraiba (Areia, Bananeiras, Conde e Remígio), which were tested for germination and sanity. The phytosanitary treatments consisted of control, dicarboximide fungicide $\left(240 \mathrm{~g} .100 \mathrm{Kg}^{-1}\right)$ and extracts of A. blanchetti and $M$. charantia at concentrations of 10, 100, 500 and $1000 \mathrm{ppm}$. We identified in the seeds of $C$. ferrea fungi Aspergillus flavus, A. niger, Cladosporium sp., R. stolonifer, Penicillium sp. and Nigrospora sp. The extracts of $A$. blanchetti and $M$. charantia in concentrations of 500 and $1000 \mathrm{ppm}$ reduced the incidence of fungi. The highest concentrations (500 and $1000 \mathrm{ppm}$ ) of both extracts increased percentage and germination rate (IVG) and length of seedlings of C. ferrea. Keywords: Pathology seed; mycoflora; alternative control; germination.
\end{abstract}

FLORESTA, Curitiba, PR, v. 45, n. 1, p. 163 - 174, jan. / mar. 2015. 


\section{INTRODUÇÃO}

Diversos fungos encontrados em sementes florestais são conhecidos por causarem doenças em espécies agrícolas ou mesmo florestais. O conhecimento dos organismos patogênicos encontrados nas sementes é apenas o princípio para o controle de sua livre disseminação. Além dessa etapa, ainda faz-se necessário identificar sua transmissão através da semente e, em caso positivo, verificar se algum desses organismos é capaz de causar doenças em plântulas ou mudas (LAZAROTTO et al., 2012).

Pertencente à família das leguminosas, Caesalpinia ferrea Mart. ex Tul., conhecida como pau-ferro, é uma planta arbórea, têm ampla dispersão e baixa densidade populacional, formando copa arredondada, fechada e densa. Possui porte que varia de 10 a $15 \mathrm{~m}$ e tronco curto, de 40 a $60 \mathrm{~cm}$ de diâmetro, com bifurcações quando isolada. A casca é externamente acinzentada, lisa e fina, com manchas brancas irregulares que contrastam com partes mais escuras, as quais se renovam anualmente, proporcionando belo efeito decorativo. Suas folhas são compostas, bipinadas, e apresenta flores amarelas e brilhantes, pequenas, reunidas em panícula terminal de até $20 \mathrm{~cm}$ de comprimento (LORENZI; MATOS, 2008).

Os fitopatógenos podem estar associados às sementes na sua superfície, no seu interior ou misturados às mesmas. Eles se apresentam nas mais variadas formas de propagação, desde o esporo até estruturas de resistência, o micélio, e outras estruturas específicas dos diversos grupos de fungos, bactérias, nematoides e vírus (SANTOS et al., 2011).

A atividade de compostos secundários de plantas tem se tornado uma alternativa no controle de fitopatógenos, com potencial ecológico para substituir o emprego de produtos sintéticos, por meio da utilização de subprodutos de plantas medicinais, como extratos etanólicos, uma vez que apresentam em sua composição substâncias com propriedades fungitóxicas (VENTUROSO et al., 2011).

A exploração da atividade biológica de compostos secundários presentes no extrato de plantas também pode se constituir em mais uma forma potencial de controle alternativo de doenças em plantas cultivadas. Dessa forma, pesquisas buscam definir o papel de cada substância participante dos processos fisiológicos de defesa das plantas (LINS et al., 2011).

Diante da necessidade de novas alternativas no estudo da associação de fungos a sementes de espécies florestais nativas, o presente trabalho objetivou avaliar a eficiência dos extratos vegetais de melão-de-são-caetano (Momordica charantia L.) e alamanda (Allamanda blanchetti A. DC.) sobre a micoflora e germinação, assim como o vigor de sementes de Caesalpinia ferrea de diferentes procedências, visando estabelecer um controle de patógenos e, consequentemente, contribuir para a preservação e conservação dessa espécie florestal, com menores impactos ao meio ambiente.

\section{MATERIAL E MÉTODOS}

O trabalho de pesquisa foi realizado nos Laboratórios de Fitopatologia e Tecnologia de Sementes do Centro de Ciências Agrárias da Universidade Federal da Paraíba, Areia, PB.

\section{Coleta e beneficiamento das sementes}

Os frutos maduros de Caesalpinia ferrea foram coletados no solo, abaixo da copa das árvores. Os lotes foram coletados em quatro matrizes nativas localizadas nos municípios de Areia, PB (Lote 1 S $\left.6^{\circ} 58^{\prime} 06^{\prime \prime} \mathrm{W} 35^{\circ} 42^{\prime} 55^{\prime \prime}\right)$, Bananeiras, PB (Lote 2 - S 6 $\left.45^{\prime} 4^{\prime \prime} \mathrm{W} 35^{\circ} 38^{\prime} 0^{\prime \prime}\right)$, Conde, PB (Lote 3 S $07^{\circ} 15^{\prime} 36^{\prime \prime}$ W $34^{\circ} 54^{\prime} 28^{\prime \prime}$ ) e Remígio, PB (Lote 4 - S 6 53 '29” W 3549'51"), no período de setembro a dezembro de 2011. Após a colheita, foram encaminhados ao Laboratório de Fitopatologia, onde foram beneficiados manualmente, com retirada das sementes. Em seguida, as sementes foram secas à sombra, armazenadas em sacos plásticos e posteriormente escarificadas utilizando-se lixa Massilla A257 $\mathrm{n}^{\circ} 80$ na região oposta ao hilo, para a superação da dormência.

\section{Determinação do teor de água nas sementes}

$\mathrm{O}$ teor de água nas sementes foi determinado utilizando-se o método da estufa a $105 \pm 3{ }^{\circ} \mathrm{C}$, por $24 \mathrm{~h}$ (BRASIL, 2009). Utilizaram-se quatro repetições de $5 \mathrm{~g}$ de sementes e os resultados foram expressos em percentagem. 


\section{Obtenção dos extratos etanólicos}

Para a obtenção dos extratos de melão-de-são-caetano e alamanda, utilizou-se o método de extração a frio, em que o material vegetal (folhas) foi seco em estufa a $40{ }^{\circ} \mathrm{C}$ durante $72 \mathrm{~h}$ e posteriormente triturado em um moinho de facas, para a obtenção do pó vegetal.

Utilizaram-se $150 \mathrm{~g}$ do pó vegetal, imerso em béquer contendo $500 \mathrm{~mL}$ de etanol absoluto durante $72 \mathrm{~h}$ em temperatura ambiente $\left(25 \pm 2{ }^{\circ} \mathrm{C}\right)$, sendo a solução filtrada em papel de filtro. Após esse procedimento, o solvente foi extraído com evaporador rotativo por aproximadamente $2 \mathrm{~h}$ a $78{ }^{\circ} \mathrm{C}$, para a obtenção do extrato bruto. O extrato bruto foi diluído para as concentrações de 10, 100, 500 e 1000 ppm.

\section{Teste de sanidade}

A avaliação da incidência de fungos nas sementes foi realizada a partir da visualização dos fungos sobre elas através do método de incubação em papel de filtro (ZAUZA et al., 2007). As sementes foram submetidas a assepsia com hipoclorito de sódio (1\%) durante 3 minutos, imersas em $10 \mathrm{~mL}$ de extrato por cinco minutos e, em seguida, incubadas em placas de Petri sobre uma camada dupla de papel de filtro esterilizada e umedecida com água destilada esterilizada (ADE). As placas permaneceram durante sete dias sob temperatura de $25 \pm 2{ }^{\circ} \mathrm{C}$.

Os tratamentos aplicados nas sementes consistiram de $\mathrm{T}_{1}$ - Testemunha (sementes não tratadas); $\mathrm{T}_{2}$ - Fungicida dicarboximida (240 g. $100 \mathrm{~kg}^{-1}$ de sementes); $\mathrm{T}_{3}$ - Extrato de alamanda (EAb) a $10 \mathrm{ppm}$; $\mathrm{T}_{4}$ - EAb 100 ppm; $\mathrm{T}_{5}$ - EAb 500 ppm; $\mathrm{T}_{6}$ - EAb 1000 ppm; $\mathrm{T}_{7}$ - Extrato de melão-de-são-caetano (EMc) a 10 ppm; $\mathrm{T}_{8}$ - EMc $100 \mathrm{ppm} ; \mathrm{T}_{9}$ - EMc 500 ppm e $\mathrm{T}_{10}$ - EMc 1000 ppm.

A detecção e identificação dos fungos foram realizadas com auxílio de microscópio óptico e estereoscópico, sendo comparadas às descrições constantes na literatura (MARTHUR; KONGSDAL, 2003).

\section{Teste de germinação}

No teste de germinação, foram utilizadas 200 sementes de cada lote, divididas em quatro repetições de 50 para cada tratamento, semeadas em papel germitest previamente esterilizado e umedecido com água destilada na proporção de 2,5 vezes o seu peso seco e incubadas em germinador do tipo Biochemical Oxigen Demand (B.O.D), regulado à temperatura alternada de $25-30{ }^{\circ} \mathrm{C}$ e fotoperíodo de 8/16 horas de luz e escuro, respectivamente.

As contagens de sementes germinadas e não germinadas foram realizadas do sétimo ao décimo quinto dia após a semeadura (LIMA et al., 2006), e as avaliações seguiram os critérios estabelecidos pelas Regras para Análise de Sementes (BRASIL, 2009).

Foram avaliadas no teste de germinação as seguintes variáveis: percentual de germinação (G), primeira contagem (PC), índice de velocidade de germinação (IVG), percentual de sementes duras (SD) e mortas (SM) e comprimento da parte aérea (CPA), da raiz (CPR) e da plântula (CPL). Para o índice de velocidade de germinação, foram realizadas contagens diárias, a partir da germinação da primeira semente no teste de germinação, até o momento em que o estande permaneceu constante.

\section{Delineamento experimental}

O delineamento experimental utilizado foi o inteiramente casualizado (DIC). O teste de sanidade consistiu em dez tratamentos, distribuídos em dez repetições de dez sementes cada, enquanto que o teste de germinação foi realizado em quatro repetições de vinte e cinco sementes por tratamento.

Os dados obtidos dos testes de sanidade, transformados em $\sqrt{x}+1$, e germinação foram submetidos à análise de variância, e as médias, separadas por local de coleta, comparadas pelo teste de Scott-Knott ao nível de $1 \%$ de significância, por meio do software estatístico SAS ${ }^{\circledR}$ (SAS, 1992). Nas tabelas são apresentadas as médias originais, sem transformação.

\section{RESULTADOS}

Análise sanitária das sementes de Caesalpinia ferrea

Na tabela 1 encontra-se a incidência dos fungos detectados nas sementes de Caesalpinia ferrea oriundas do município de Areia, PB (Lote 1), que foram Aspergillus niger, A. flavus, Rhizopus stolonifer, Penicillium sp. e Nigrospora sp.

Observa-se que todas as concentrações do extrato de Allamanda blanchetti (EAb) foram eficientes na redução do crescimento de $R$. stolonifer. As concentrações de $500\left(\mathrm{~T}_{5}\right)$ e $1000\left(\mathrm{~T}_{6}\right)$ ppm reduziram a incidência de A. niger e Nigrospora sp. 
O extrato de Momordica charantia, em todas as concentrações testadas, proporcionou a redução na incidência de $R$. stolonifer e Nigrospora sp. As concentrações de $500\left(\mathrm{~T}_{9}\right)$ e $1000\left(\mathrm{~T}_{10}\right)$ ppm apresentaram ação fungitóxica sobre os fungos A. niger e A. flavus. No entanto, não foi observada diferença significativa entre os tratamentos na redução da frequência de Penicillium sp. (Tabela 1).

Tabela 1. Incidência e efeito dos extratos vegetais sobre a micoflora em sementes de Caesalpinia ferrea coletadas em Areia, PB (Lote 1).

Table 1. Incidence and effect of plant extracts on the mycoflora on seeds of Caesalpinia ferrea collected at Areia, PB (Seed Lot 1).

\begin{tabular}{|c|c|c|c|c|c|}
\hline \multirow{2}{*}{ Tratamentos } & \multicolumn{5}{|c|}{ Incidência de fungos (\%) } \\
\hline & $\begin{array}{c}\text { Aspergillus } \\
\text { niger }\end{array}$ & $\begin{array}{c}\text { Aspergillus } \\
\text { flavus }\end{array}$ & $\begin{array}{l}\text { Rhizopus } \\
\text { stolonifer }\end{array}$ & $\begin{array}{c}\begin{array}{c}\text { Penicillium } \\
\text { sp. }\end{array} \\
\end{array}$ & $\begin{array}{c}\text { Nigrospora } \\
\text { sp. }\end{array}$ \\
\hline $\mathrm{T}_{1}-$ Testemunha & $20,0 \mathrm{a}$ & $29,0 \mathrm{a}$ & $17,0 \mathrm{a}$ & $19,0 \mathrm{a}$ & $25,0 \mathrm{a}$ \\
\hline $\mathrm{T}_{2}$ - Fungicida & $0,0 \mathrm{~b}$ & $1,0 \mathrm{~b}$ & $0,0 \mathrm{~b}$ & $2,0 \mathrm{a}$ & $0,0 \mathrm{c}$ \\
\hline $\mathrm{T}_{3}-\mathrm{EAb} 10 \mathrm{ppm}$ & $22,0 \mathrm{a}$ & 26,0 a & $9,0 \mathrm{~b}$ & $9,0 \mathrm{a}$ & $11,0 \mathrm{~b}$ \\
\hline $\mathrm{T}_{4}-\mathrm{EAb} 100 \mathrm{ppm}$ & $16,0 \mathrm{a}$ & 26,0 a & $8,0 \mathrm{~b}$ & $7,0 \mathrm{a}$ & $11,0 \mathrm{~b}$ \\
\hline $\mathrm{T}_{5}-\mathrm{EAb} 500 \mathrm{ppm}$ & $10,0 \mathrm{~b}$ & $29,0 \mathrm{a}$ & $5,0 \mathrm{~b}$ & $7,0 \mathrm{a}$ & $14,0 \mathrm{~b}$ \\
\hline $\mathrm{T}_{6}-\mathrm{EAb} 1000 \mathrm{ppm}$ & $10,0 \mathrm{~b}$ & $19,0 \mathrm{a}$ & $8,0 \mathrm{~b}$ & $14,0 \mathrm{a}$ & $11,0 \mathrm{~b}$ \\
\hline $\mathrm{T}_{7}-\mathrm{EMc} 10 \mathrm{ppm}$ & $19,0 \mathrm{a}$ & $22,0 \mathrm{a}$ & $7,0 \mathrm{~b}$ & $16,0 \mathrm{a}$ & $6,0 \mathrm{c}$ \\
\hline $\mathrm{T}_{8}-\mathrm{EMc} 100 \mathrm{ppm}$ & $12,0 \mathrm{~b}$ & $27,0 \mathrm{a}$ & $4,0 \mathrm{~b}$ & $7,0 \mathrm{a}$ & $5,0 \mathrm{c}$ \\
\hline $\mathrm{T}_{9}-\mathrm{EMc} 500 \mathrm{ppm}$ & $9,0 \mathrm{~b}$ & $12,0 \mathrm{~b}$ & $2,0 \mathrm{~b}$ & $8,0 \mathrm{a}$ & $5,0 \mathrm{c}$ \\
\hline $\mathrm{T}_{10^{-}} \mathrm{EMc} 1000 \mathrm{ppm}$ & $7,0 \mathrm{~b}$ & $12,0 \mathrm{~b}$ & $3,0 \mathrm{~b}$ & $11,0 \mathrm{a}$ & $1,0 \mathrm{c}$ \\
\hline $\mathrm{CV}(\%)$ & 25,9 & 16,8 & 31,6 & 25,1 & 41,3 \\
\hline D.M.S. & 1,11 & 1,23 & 0,70 & 0,96 & 0,97 \\
\hline
\end{tabular}

Médias seguidas pela mesma letra na coluna não diferem entre si pelo teste de Scott-Knott a 1\% de probabilidade. CV: coeficiente de variação; D.M.S.: desvio médio significativo.

A micoflora presente nas sementes de $C$. ferrea coletadas no município de Bananeiras, PB (Lote 2), constituiu-se dos gêneros Aspergillus flavus, A. niger, Rhizopus stolonifer e Penicillium sp. (Tabela 2).

Tabela 2. Incidência e efeito dos extratos vegetais sobre a micoflora em sementes de Caesalpinia ferrea coletadas no município de Bananeiras, PB (Lote 2).

Table 2. Incidence and effect of plant extracts on the mycoflora on seeds of Caesalpinia ferrea collected at Bananeiras, PB (Seed Lot 2).

\begin{tabular}{|c|c|c|c|c|}
\hline \multirow{2}{*}{ Tratamentos } & \multicolumn{4}{|c|}{ Incidência de fungos (\%) } \\
\hline & Aspergillus niger & Aspergillus flavus & Rhizopus stolonifer & Penicillium sp. \\
\hline $\mathrm{T}_{1}-$ Testemunha & $25,0 \mathrm{a}$ & $30,0 \mathrm{a}$ & $12,0 \mathrm{a}$ & $24,0 \mathrm{a}$ \\
\hline $\mathrm{T}_{2}$ - Fungicida & $0,0 \mathrm{~b}$ & $0,0 \mathrm{c}$ & $1,0 \mathrm{~b}$ & $0,0 \mathrm{~b}$ \\
\hline $\mathrm{T}_{3}-\mathrm{EAb} 10 \mathrm{ppm}$ & $23,0 \mathrm{a}$ & $28,0 \mathrm{a}$ & $5,0 \mathrm{~b}$ & $14,0 \mathrm{a}$ \\
\hline $\mathrm{T}_{4}-\mathrm{EAb} 100 \mathrm{ppm}$ & $17,0 \mathrm{a}$ & $30,0 \mathrm{a}$ & $5,0 \mathrm{~b}$ & $14,0 \mathrm{a}$ \\
\hline $\mathrm{T}_{5}-\mathrm{EAb} 500 \mathrm{ppm}$ & $12,0 \mathrm{~b}$ & $34,0 \mathrm{a}$ & $3,0 \mathrm{~b}$ & $15,0 \mathrm{a}$ \\
\hline $\mathrm{T}_{6}-\mathrm{EAb} 1000 \mathrm{ppm}$ & $8,0 \mathrm{~b}$ & $25,0 \mathrm{a}$ & $5,0 \mathrm{~b}$ & $18,0 \mathrm{a}$ \\
\hline $\mathrm{T}_{7}-\mathrm{EMc} 10 \mathrm{ppm}$ & $17,0 \mathrm{a}$ & $27,0 \mathrm{a}$ & $5,0 \mathrm{~b}$ & $21,0 \mathrm{a}$ \\
\hline $\mathrm{T}_{8}-\mathrm{EMc} 100 \mathrm{ppm}$ & $6,0 \mathrm{~b}$ & $31,0 \mathrm{a}$ & $2,0 \mathrm{~b}$ & $5,0 \mathrm{~b}$ \\
\hline $\mathrm{T}_{9}-\mathrm{EMc} 500 \mathrm{ppm}$ & $7,0 \mathrm{~b}$ & $16,0 \mathrm{~b}$ & $1,0 \mathrm{~b}$ & $9,0 \mathrm{~b}$ \\
\hline $\mathrm{T}_{10}-\mathrm{EMc} 1000 \mathrm{ppm}$ & $5,0 \mathrm{~b}$ & $9,0 \mathrm{~b}$ & $0,0 \mathrm{~b}$ & $7,0 \mathrm{~b}$ \\
\hline $\mathrm{CV}(\%)$ & 29,1 & 19,9 & 37,9 & 21,5 \\
\hline D.M.S. & 0,98 & 1,27 & 0,56 & 1,06 \\
\hline
\end{tabular}

Médias seguidas pela mesma letra na coluna não diferem entre si pelo teste de Scott-Knott a 1\% de probabilidade. CV:coeficiente de variação; D.M.S.: desvio médio significativo.

Todas as concentrações dos extratos de $M$. charantia e $A$. blanchetti reduziram a frequência de R. stolonifer. As maiores concentrações do extrato de M. charantia (500 e $1000 \mathrm{ppm})$ reduziram o crescimento de A. niger, A. flavus e Penicillium sp. O extrato de A. blanchetti nas concentrações de $500\left(\mathrm{~T}_{5}\right)$ e $1000\left(\mathrm{~T}_{6}\right)$ ppm diminuiu a ocorrência de A. niger (Tabela 2). 
A tabela 3 apresenta a incidência e a micoflora detectada nas sementes de $C$. ferrea coletadas no município do Conde, PB (Lote 3). Foram identificados os fungos Aspergillus niger, A. flavus, Rhizopus stolonifer, Cladosporium sp. e Penicillium sp.

Tabela 3. Incidência e efeito dos extratos vegetais sobre a micoflora em sementes de Caesalpinia ferrea coletadas no município do Conde, PB (Lote 3).

Table 3. Incidence and effect of plant extracts on the mycoflora on seeds of Caesalpinia ferrea collected at Conde, PB (Seed Lot 3).

\begin{tabular}{|c|c|c|c|c|c|}
\hline \multirow[b]{2}{*}{ Tratamentos } & \multicolumn{5}{|c|}{ Incidência de fungos (\%) } \\
\hline & $\begin{array}{c}\text { Aspergillus } \\
\text { niger }\end{array}$ & $\begin{array}{c}\text { Aspergillus } \\
\text { Flavus }\end{array}$ & $\begin{array}{l}\text { Rhizopus } \\
\text { stolonifer }\end{array}$ & $\begin{array}{c}\text { Cladosporium } \\
\text { sp. }\end{array}$ & $\begin{array}{c}\text { Penicillium } \\
\text { sp. }\end{array}$ \\
\hline $\mathrm{T}_{1}-$ Testemunha & $14,0 \mathrm{a}$ & $23,0 \mathrm{a}$ & $15,0 \mathrm{a}$ & $16,0 \mathrm{a}$ & $13,0 \mathrm{a}$ \\
\hline $\mathrm{T}_{2}$ - Fungicida & $0,0 \mathrm{~b}$ & $2,0 \mathrm{~b}$ & $0,0 \mathrm{~b}$ & $0,0 \mathrm{~b}$ & $0,0 \mathrm{~b}$ \\
\hline $\mathrm{T}_{3}-\mathrm{EAb} 10 \mathrm{ppm}$ & $14,0 \mathrm{a}$ & $23,0 \mathrm{a}$ & $12,0 \mathrm{a}$ & $14,0 \mathrm{a}$ & $10,0 \mathrm{a}$ \\
\hline $\mathrm{T}_{4}-\mathrm{EAb} 100 \mathrm{ppm}$ & $8,0 \mathrm{~b}$ & $19,0 \mathrm{a}$ & $13,0 \mathrm{a}$ & $6,0 \mathrm{~b}$ & $4,0 \mathrm{a}$ \\
\hline $\mathrm{T}_{5}-\mathrm{EAb} 500 \mathrm{ppm}$ & $4,0 \mathrm{~b}$ & $25,0 \mathrm{a}$ & $11,0 \mathrm{a}$ & $6,0 \mathrm{~b}$ & $11,0 \mathrm{a}$ \\
\hline $\mathrm{T}_{6}-\mathrm{EAb} 1000 \mathrm{ppm}$ & $7,0 \mathrm{~b}$ & $16,0 \mathrm{a}$ & $13,0 \mathrm{a}$ & $7,0 \mathrm{~b}$ & $13,0 \mathrm{a}$ \\
\hline $\mathrm{T}_{7}-\mathrm{EMc} 10 \mathrm{ppm}$ & $14,0 \mathrm{a}$ & $16,0 \mathrm{a}$ & $10,0 \mathrm{a}$ & $6,0 \mathrm{~b}$ & $3,0 \mathrm{~b}$ \\
\hline $\mathrm{T}_{8}-\mathrm{EMc} 100 \mathrm{ppm}$ & $7,0 \mathrm{~b}$ & $19,0 \mathrm{a}$ & $4,0 \mathrm{~b}$ & $3,0 \mathrm{~b}$ & $2,0 \mathrm{~b}$ \\
\hline $\mathrm{T}_{9}-\mathrm{EMc} 500$ ppm & $7,0 \mathrm{~b}$ & $12,0 \mathrm{~b}$ & $7,0 \mathrm{~b}$ & $2,0 \mathrm{~b}$ & $4,0 \mathrm{~b}$ \\
\hline $\mathrm{T}_{10}-\mathrm{EMc} 1000 \mathrm{ppm}$ & $3,0 \mathrm{~b}$ & $7,0 \mathrm{~b}$ & $2,0 \mathrm{~b}$ & $0,0 \mathrm{~b}$ & $0,0 \mathrm{~b}$ \\
\hline $\mathrm{CV}(\%)$ & 23,5 & 31,9 & 27,3 & 29,0 & 46,1 \\
\hline D.M.S. & 0,84 & 1,30 & 0,88 & 0,78 & 0,69 \\
\hline
\end{tabular}

Médias seguidas pela mesma letra na coluna não diferem entre si pelo teste de Scott-Knott a 1\% de probabilidade. CV: coeficiente de variação; D.M.S.: desvio médio significativo.

Em relação ao extrato de $M$. charantia, observou-se que todas as concentrações reduziram a incidência de Cladosporium sp. e Penicillium sp. As concentrações de $500\left(\mathrm{~T}_{9}\right)$ e $1000\left(\mathrm{~T}_{10}\right)$ ppm reduziram a ocorrência dos fungos A. niger, $R$. stolonifer e A. flavus. $\mathrm{O}$ extrato de A. blanchetti nas concentrações de $100\left(\mathrm{~T}_{4}\right), 500\left(\mathrm{~T}_{5}\right)$ e $1000\left(\mathrm{~T}_{6}\right)$ ppm diminuiu a frequência de A. niger e Cladosporium sp. (Tabela 3).

No lote de sementes colhido no município de Remígio, PB (Lote 4), foram observados os fungos Aspergillus niger, A. flavus, Rhizopus stolonifer e Penicillium sp. (Tabela 4).

Tabela 4. Incidência e efeito dos extratos vegetais sobre a micoflora em sementes de Caesalpinia ferrea coletadas no município de Remígio, PB (Lote 4).

Table 4. Incidence and effect of plant extracts on the mycoflora on seeds of Caesalpinia ferrea collected at Remígio, PB (Seed Lot 4).

\begin{tabular}{|c|c|c|c|c|}
\hline \multirow[b]{2}{*}{ Tratamentos } & \multicolumn{4}{|c|}{ Incidência de fungos (\%) } \\
\hline & $\begin{array}{c}\text { Aspergillus } \\
\text { niger }\end{array}$ & $\begin{array}{l}\text { Aspergillus } \\
\text { flavus }\end{array}$ & $\begin{array}{l}\text { Rhizopus } \\
\text { stolonifer }\end{array}$ & $\begin{array}{c}\text { Penicillium } \\
\text { sp. }\end{array}$ \\
\hline $\mathrm{T}_{1}$ - Testemunha & $24,0 \mathrm{a}$ & $27,0 \mathrm{a}$ & $13,0 \mathrm{a}$ & $15,0 \mathrm{a}$ \\
\hline $\mathrm{T}_{2}$ - Fungicida & $0,0 \mathrm{~b}$ & $0,0 \mathrm{~b}$ & $1,0 \mathrm{~b}$ & $0,0 \mathrm{~b}$ \\
\hline $\mathrm{T}_{3}-\mathrm{EAb} 10 \mathrm{ppm}$ & $21,0 \mathrm{a}$ & $21,0 \mathrm{a}$ & $13,0 \mathrm{a}$ & $18,0 \mathrm{a}$ \\
\hline $\mathrm{T}_{4}-\mathrm{EAb} 100 \mathrm{ppm}$ & $21,0 \mathrm{a}$ & $19,0 \mathrm{a}$ & $15,0 \mathrm{a}$ & $21,0 \mathrm{a}$ \\
\hline $\mathrm{T}_{5^{-}} \mathrm{EAb} 500 \mathrm{ppm}$ & $20,0 \mathrm{a}$ & $19,0 \mathrm{a}$ & $14,0 \mathrm{a}$ & $20,0 \mathrm{a}$ \\
\hline $\mathrm{T}_{6}-\mathrm{EAb} 1000 \mathrm{ppm}$ & $22,0 \mathrm{a}$ & $19,0 \mathrm{a}$ & $14,0 \mathrm{a}$ & $14,0 \mathrm{a}$ \\
\hline $\mathrm{T}_{7^{-}}$EMc $10 \mathrm{ppm}$ & $19,0 \mathrm{a}$ & $16,0 \mathrm{a}$ & $6,0 \mathrm{~b}$ & $16,0 \mathrm{a}$ \\
\hline $\mathrm{T}_{8}-\mathrm{EMc} 100 \mathrm{ppm}$ & $9,0 \mathrm{~b}$ & $19,0 \mathrm{a}$ & $2,0 \mathrm{~b}$ & $7,0 \mathrm{~b}$ \\
\hline $\mathrm{T}_{9}-\mathrm{EMc} 500 \mathrm{ppm}$ & $6,0 \mathrm{~b}$ & $7,0 \mathrm{~b}$ & $3,0 \mathrm{~b}$ & $6,0 \mathrm{~b}$ \\
\hline $\mathrm{T}_{10^{-}} \mathrm{EMc} 1000 \mathrm{ppm}$ & $3,0 \mathrm{~b}$ & $5,0 \mathrm{~b}$ & $2,0 \mathrm{~b}$ & $6,0 \mathrm{~b}$ \\
\hline $\mathrm{CV}(\%)$ & 24,2 & 31,5 & 34,8 & 25,6 \\
\hline D.M.S & 1,09 & 1,10 & 0,63 & 0,84 \\
\hline
\end{tabular}

Médias seguidas pela mesma letra na coluna não diferem entre si pelo teste de Scott-Knott a 1\% de probabilidade. CV: coeficiente de variação; D.M.S.: desvio médio significativo. 
O extrato de $M$. charantia em todas as concentrações testadas reduziu a incidência de $R$. stolonifer, enquanto que nas concentrações de $500\left(\mathrm{~T}_{9}\right)$ e $1000\left(\mathrm{~T}_{10}\right)$ ppm reduziu o crescimento de A. niger, A. flavus e Penicillium sp. Não houve diferença entre os tratamentos quando utilizado o extrato de A. blanchetti (Tabela 4).

\section{Análise da qualidade fisiológica das sementes de Caesalpinia ferrea}

Para os testes de germinação e vigor, verificou-se que os graus de umidade das sementes foram 6,$31 ; 7,47 ; 6,80$ e 6,53\% para os lotes provenientes dos municípios de Areia, Bananeiras, Conde e Remígio, respectivamente.

Na tabela 5 encontram-se os dados referentes à qualidade fisiológica de sementes de $C$. ferrea coletadas do município de Areia (Lote 1).

Tabela 5. Valores médios de germinação (G), primeira contagem (PC), sementes mortas (SM) e duras (SD), comprimentos da parte aérea (CPA), raiz (CPR), plântula (CPL) e índice de velocidade de germinação (IVG) de sementes de Caesalpinia ferrea coletadas em Areia, PB (Lote 1) e tratadas com extratos de Allamanda blanchetti e Momordica charantia.

Table 5. Average values of germination (G), first count (PC), dead seeds (SM) and hard (SD), length of shoot (CPA), root (CPR), seedling (CPL) and germination speed index (GSI) of Caesalpinia ferrea collected at Areia (Seed Lot 1) and treated with extracts of Allamanda blanchetti and Momordica charantia.

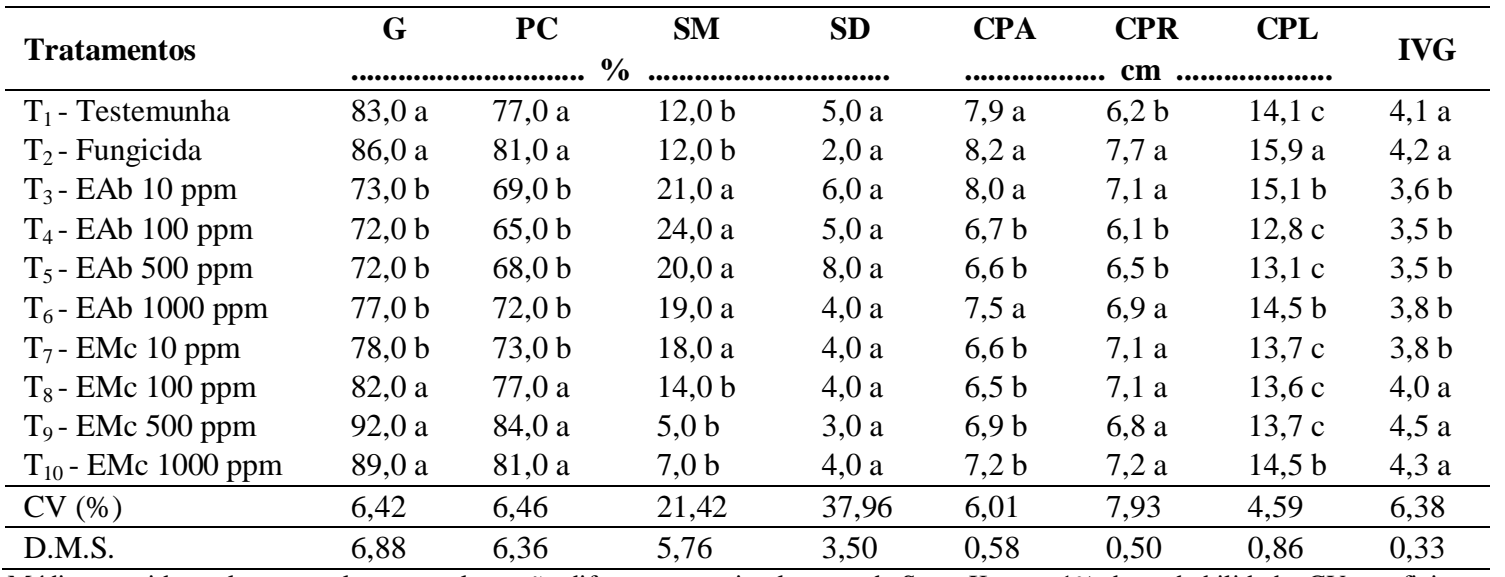

Médias seguidas pela mesma letra na coluna não diferem entre si pelo teste de Scott-Knott a 1\% de probabilidade. CV: coeficiente de variação; D.M.S.: desvio médio significativo.

Quanto ao percentual de germinação, observou-se que sementes tratadas com fungicida $\left(\mathrm{T}_{2}\right) \mathrm{e}$ extrato de $M$. charantia, nas concentrações de $100\left(\mathrm{~T}_{8}\right), 500\left(\mathrm{~T}_{9}\right)$ e $1000\left(\mathrm{~T}_{10}\right)$ ppm, variaram entre 86 e $92 \%$ e não diferiram estatisticamente da testemunha $\left(\mathrm{T}_{1}\right)$, com $83 \%$. Os tratamentos com o extrato de A. blanchetti (10, 100, 500 e $1000 \mathrm{ppm})$ comprometeram significativamente o desempenho germinativo das sementes de $C$. ferrea, com resultados inferiores ao da testemunha $\left(\mathrm{T}_{1}\right)$ (Tabela 5).

$\mathrm{O}$ extrato de $A$. blanchetti (10, 100, 500 e $1000 \mathrm{ppm})$ promoveu aumento significativo do percentual de sementes mortas em relação à testemunha $\left(\mathrm{T}_{1}\right)$, enquanto que os menores percentuais foram verificados nas sementes tratadas com fungicida $\left(\mathrm{T}_{2}\right)$ e extrato de $M$. charantia nas concentrações de $100\left(\mathrm{~T}_{8}\right), 500\left(\mathrm{~T}_{9}\right)$ e $1000\left(\mathrm{~T}_{10}\right)$ ppm. No entanto, para o percentual de sementes duras não houve diferença estatística entre os tratamentos (Tabela 5).

Os tratamentos com fungicida $\left(\mathrm{T}_{2}\right)$ e extrato de $A$. blanchetti nas concentrações de $10\left(\mathrm{~T}_{3}\right)$ e $1000\left(\mathrm{~T}_{6}\right)$ ppm proporcionaram maiores comprimentos da parte aérea de plântulas de $C$. ferrea, embora sem diferir da testemunha $\left(\mathrm{T}_{1}\right)$. Para o comprimento da raiz, os tratamentos com fungicida $\left(\mathrm{T}_{2}\right)$, A. blanchetti a $10\left(\mathrm{~T}_{3}\right)$ e $1000\left(\mathrm{~T}_{6}\right)$ ppm e $M$. charantia em todas as concentrações testadas promoveram resultados superiores em relação aos demais tratamentos avaliados (Tabela 5).

Em relação ao IVG, observou-se que os tratamentos com o extrato de $M$. charantia nas concentrações de $100\left(\mathrm{~T}_{8}\right), 500\left(\mathrm{~T}_{9}\right)$ e $1000\left(\mathrm{~T}_{10}\right)$ ppm proporcionaram maior velocidade de germinação em relação aos demais, não diferindo do tratamento com fungicida $\left(\mathrm{T}_{2}\right)$ e da testemunha $\left(\mathrm{T}_{1}\right)$. Todas as 
concentrações do extrato de A. blanchetti reduziram significativamente o índice de velocidade de germinação, com resultados inferiores comparados à testemunha $\left(T_{1}\right)$ (Tabela 5).

$\mathrm{Na}$ tabela 6 estão apresentados os resultados da qualidade fisiológica de sementes de $C$. ferrea oriundas do município de Bananeiras (Lote 2) tratadas com extratos de Allamanda blanchetti e Momordica charantia.

Tabela 6. Valores médios de germinação (G), primeira contagem (PC), sementes mortas (SM) e duras (SD), comprimentos da parte aérea (CPA), raiz (CPR), plântula (CPL) e índice de velocidade de germinação (IVG), em sementes de Caesalpinia ferrea coletadas em Bananeiras, PB (Lote 2) e tratadas com extratos de Allamanda blanchetti e Momordica charantia.

Table 6. Average values of germination (G), first count (PC), dead seeds (SM) and hard (SD), length of shoot (CPA), root (CPR), seedling (CPL) and germination speed index (GSI) of Caesalpinia ferrea collected at Bananeiras, PB (Seed Lot 2) and treated with extracts of Allamanda blanchetti and Momordica charantia.

\begin{tabular}{|c|c|c|c|c|c|c|c|c|}
\hline \multirow{2}{*}{ Tratamentos } & $\mathbf{G}$ & PC & SM & SD & CPA & CPR & CPL & \multirow{2}{*}{ IVG } \\
\hline & \multicolumn{4}{|c|}{ 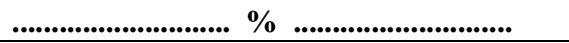 } & \multicolumn{3}{|c|}{ 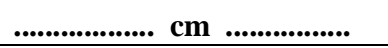 } & \\
\hline $\mathrm{T}_{1}$ - Testemunha & $78,0 \mathrm{~b}$ & $69,0 \mathrm{c}$ & $19,0 \mathrm{a}$ & $11,0 \mathrm{a}$ & $6,5 \mathrm{a}$ & $4,8 \mathrm{c}$ & $10,9 \mathrm{~b}$ & $3,8 \mathrm{~b}$ \\
\hline $\mathrm{T}_{2}$ - Fungicida & $90,0 \mathrm{a}$ & $85,0 \mathrm{a}$ & $9,0 \mathrm{~b}$ & $1,0 \mathrm{c}$ & $6,2 \mathrm{a}$ & $7,4 \mathrm{a}$ & $13,6 \mathrm{a}$ & $4,4 \mathrm{a}$ \\
\hline $\mathrm{T}_{3}-\mathrm{EAb} 10 \mathrm{ppm}$ & $72,0 \mathrm{c}$ & $68,0 \mathrm{c}$ & $21,0 \mathrm{a}$ & $7,0 \mathrm{~b}$ & $5,5 \mathrm{a}$ & $5,9 \mathrm{~b}$ & $11,4 \mathrm{~b}$ & $3,5 \mathrm{c}$ \\
\hline $\mathrm{T}_{4}-\mathrm{EAb} 100 \mathrm{ppm}$ & $70,0 \mathrm{c}$ & $66,0 \mathrm{c}$ & $27,0 \mathrm{a}$ & $3,0 \mathrm{c}$ & $6,0 \mathrm{a}$ & $5,5 \mathrm{~b}$ & $11,6 \mathrm{~b}$ & $3,4 \mathrm{c}$ \\
\hline $\mathrm{T}_{5}-\mathrm{EAb} 500 \mathrm{ppm}$ & $65,0 \mathrm{c}$ & $67,0 \mathrm{c}$ & $20,0 \mathrm{a}$ & $3,0 \mathrm{c}$ & $6,2 \mathrm{a}$ & $6,6 \mathrm{a}$ & $12,8 \mathrm{a}$ & $3,5 \mathrm{c}$ \\
\hline $\mathrm{T}_{6}-\mathrm{EAb} 1000 \mathrm{ppm}$ & $79,0 \mathrm{~b}$ & $74,0 \mathrm{~b}$ & $20,0 \mathrm{a}$ & $1,0 \mathrm{c}$ & $6,6 \mathrm{a}$ & $6,9 \mathrm{a}$ & $13,5 \mathrm{a}$ & $3,9 \mathrm{~b}$ \\
\hline $\mathrm{T}_{7}-\mathrm{EMc} 10 \mathrm{ppm}$ & $79,0 \mathrm{~b}$ & $71,0 \mathrm{c}$ & $20,0 \mathrm{a}$ & $1,0 \mathrm{c}$ & $6,0 \mathrm{a}$ & $6,8 \mathrm{a}$ & $12,9 \mathrm{a}$ & $3,8 \mathrm{~b}$ \\
\hline $\mathrm{T}_{8}-\mathrm{EMc} 100 \mathrm{ppm}$ & $80,0 \mathrm{~b}$ & $68,0 \mathrm{c}$ & $18,0 \mathrm{a}$ & $2,0 \mathrm{c}$ & $6,4 \mathrm{a}$ & $7,1 \mathrm{a}$ & $13,5 \mathrm{a}$ & $3,8 \mathrm{~b}$ \\
\hline $\mathrm{T}_{9}-\mathrm{EMc} 500 \mathrm{ppm}$ & $88,0 \mathrm{a}$ & $76,0 \mathrm{~b}$ & $11,0 \mathrm{~b}$ & $1,0 \mathrm{c}$ & $6,3 \mathrm{a}$ & $7,0 \mathrm{a}$ & $13,3 \mathrm{a}$ & $4,2 \mathrm{a}$ \\
\hline $\mathrm{T}_{10}-\mathrm{EMc} 1000 \mathrm{ppm}$ & $89,0 \mathrm{a}$ & $77,0 \mathrm{~b}$ & $10,0 \mathrm{~b}$ & $1,0 \mathrm{c}$ & $6,9 \mathrm{a}$ & $7,5 \mathrm{a}$ & $14,5 \mathrm{a}$ & $4,3 \mathrm{a}$ \\
\hline $\mathrm{CV}(\%)$ & 7,51 & 7,56 & 22,79 & 30,75 & 7,77 & 6,56 & 5,13 & 6,76 \\
\hline D.M.S & 7,70 & 5,73 & 6,05 & 3,10 & 0,43 & 0,74 & 1,03 & 0,33 \\
\hline
\end{tabular}

Médias seguidas pela mesma letra na coluna não diferem entre si pelo teste de Scott-Knott a 1\% de probabilidade. CV: coeficiente de variação; D.M.S.: desvio médio significativo.

As maiores concentrações do extrato de $M$. charantia (500 e 1000 ppm) favoreceram o processo germinativo, proporcionando maiores resultados na primeira contagem e na avaliação final, diferindo estatisticamente da testemunha $\left(T_{1}\right)$ (Tabela 6$)$.

Os menores percentuais de sementes mortas foram verificados nos tratamentos com fungicida $\left(\mathrm{T}_{2}\right)$ e com extrato de $M$. charantia a $500\left(\mathrm{~T}_{9}\right)$ e $1000\left(\mathrm{~T}_{10}\right)$ ppm. Já o maior percentual de sementes duras foi registrado na testemunha $\left(\mathrm{T}_{1}\right)$, diferindo significativamente dos demais tratamentos (Tabela 6).

Para o comprimento da parte aérea não houve diferença estatística entre os tratamentos testados, enquanto que no comprimento da raiz todos os tratamentos superaram a testemunha $\left(T_{1}\right)$. Em relação ao comprimento de plântulas, com exceção do extrato de A. blanchetti a $10\left(\mathrm{~T}_{3}\right)$ e $100\left(\mathrm{~T}_{4}\right)$ ppm, os demais tratamentos proporcionaram diferença significativa da testemunha $\left(\mathrm{T}_{1}\right)$ (Tabela 6).

Os maiores índices de velocidade de germinação (IVG) foram registrados nos tratamentos com o extrato de M. charantia nas concentrações de $500\left(\mathrm{~T}_{9}\right)$ e $1000\left(\mathrm{~T}_{10}\right) \mathrm{ppm}$, diferindo significativamente da testemunha $\left(\mathrm{T}_{1}\right)$ (Tabela 6).

Os dados relativos à germinação e vigor de sementes de $C$. ferrea, coletadas no município do Conde (Lote 3) e tratadas com extratos de Allamanda blanchetti e Momordica charantia estão contidos na tabela 7.

As sementes tratadas com fungicida $\left(\mathrm{T}_{2}\right)$, extrato de A. blanchetti em todas as concentrações testadas e M. charantia a $1000\left(\mathrm{~T}_{10}\right)$ ppm levaram a ganhos significativos no percentual de germinação em relação à testemunha $\left(\mathrm{T}_{1}\right)$. Com relação à primeira contagem da germinação, observou-se a mesma tendência do percentual de germinação na avaliação final (Tabela 7).

Os tratamentos com extrato de $M$. charantia nas concentrações de $10\left(\mathrm{~T}_{7}\right)$ e $100\left(\mathrm{~T}_{8}\right)$ ppm resultaram em alto percentual de sementes mortas em relação à testemunha. Quanto ao percentual de sementes duras, observou-se que o tratamento com M. charantia a $500 \mathrm{ppm}\left(\mathrm{T}_{9}\right)$ apresentou maior resultado, diferindo significativamente dos demais (Tabela 7). 
Tabela 7. Valores médios de germinação (G), primeira contagem (PC), sementes mortas (SM) e duras (SD), comprimentos da parte aérea (CPA), raiz (CPR), plântula (CPL) e índice de velocidade de germinação (IVG), em sementes de Caesalpinia ferrea coletadas no Conde, PB (Lote 3) e tratadas com extratos de Allamanda blanchetti e Momordica charantia.

Table 7. Average values of germination (G), first count (PC), dead seeds (SM) and hard (SD), length of shoot (CPA), root (CPR), seedling (CPL) and germination speed index (GSI) of Caesalpinia ferrea collected at Conde, PB (Seed Lot 3) and treated with extracts of Allamanda blanchetti and Momordica charantia.

\begin{tabular}{|c|c|c|c|c|c|c|c|c|}
\hline Tratamentos & G & PC & SM & SD & CPA & CPR & CPL & IVG \\
\hline $\mathrm{T}_{1}$ - Testemunha & \multicolumn{3}{|c|}{.........\% } & $\ldots .$. & \multicolumn{3}{|c|}{ cm .... } & $3,9 \mathrm{~b}$ \\
\hline $\mathrm{T}_{2}$ - Fungicida & $88,0 \mathrm{a}$ & $79,0 \mathrm{a}$ & $9,0 \mathrm{~b}$ & $4,0 \mathrm{~b}$ & $6,5 \mathrm{~b}$ & $6,3 \mathrm{a}$ & $12,8 \mathrm{~b}$ & $4,2 \mathrm{a}$ \\
\hline $\mathrm{T}_{3}-\mathrm{EAb} 10 \mathrm{ppm}$ & $86,0 \mathrm{a}$ & $77,0 \mathrm{a}$ & $12,0 \mathrm{~b}$ & $2,0 \mathrm{~b}$ & $7,5 \mathrm{a}$ & $6,8 \mathrm{a}$ & $14,4 \mathrm{a}$ & $4,2 \mathrm{a}$ \\
\hline $\mathrm{T}_{4}-\mathrm{EAb} 100 \mathrm{ppm}$ & $86,0 \mathrm{a}$ & $74,0 \mathrm{a}$ & $11,0 \mathrm{~b}$ & $3,0 \mathrm{~b}$ & $6,5 \mathrm{~b}$ & $6,8 \mathrm{a}$ & $13,3 \mathrm{~b}$ & $4,1 \mathrm{a}$ \\
\hline $\mathrm{T}_{5}-\mathrm{EAb} 500 \mathrm{ppm}$ & $89,0 \mathrm{a}$ & $78,0 \mathrm{a}$ & $10,0 \mathrm{~b}$ & $1,0 \mathrm{~b}$ & $7,0 \mathrm{~b}$ & $7,7 \mathrm{a}$ & $14,7 \mathrm{a}$ & $4,3 \mathrm{a}$ \\
\hline $\mathrm{T}_{6}-\mathrm{EAb} 1000 \mathrm{ppm}$ & $93,0 \mathrm{a}$ & $83,0 \mathrm{a}$ & $6,0 \mathrm{~b}$ & $1,0 \mathrm{~b}$ & $8,0 \mathrm{a}$ & $6,1 \mathrm{a}$ & $14,1 \mathrm{a}$ & $4,5 \mathrm{a}$ \\
\hline $\mathrm{T}_{7}-\mathrm{EMc} 10 \mathrm{ppm}$ & $75,0 \mathrm{~b}$ & $66,0 \mathrm{~b}$ & $21,0 \mathrm{a}$ & $4,0 \mathrm{~b}$ & $6,7 \mathrm{~b}$ & $6,5 \mathrm{a}$ & $13,2 \mathrm{~b}$ & $3,6 \mathrm{~b}$ \\
\hline $\mathrm{T}_{8}-\mathrm{EMc} 100 \mathrm{ppm}$ & $78,0 \mathrm{~b}$ & $67,0 \mathrm{~b}$ & $20,0 \mathrm{a}$ & $2,0 \mathrm{~b}$ & $6,6 \mathrm{~b}$ & $6,6 \mathrm{a}$ & $13,3 \mathrm{~b}$ & $3,7 \mathrm{~b}$ \\
\hline $\mathrm{T}_{9}-\mathrm{EMc} 500 \mathrm{ppm}$ & $79,0 \mathrm{~b}$ & $66,0 \mathrm{~b}$ & $13,0 \mathrm{~b}$ & $8,0 \mathrm{a}$ & $7,5 \mathrm{a}$ & $6,7 \mathrm{a}$ & $14,2 \mathrm{a}$ & $3,7 \mathrm{~b}$ \\
\hline $\mathrm{T}_{10}-\mathrm{EMc} 1000 \mathrm{ppm}$ & $85,0 \mathrm{a}$ & $72,0 \mathrm{~b}$ & $12,0 \mathrm{~b}$ & $3,0 \mathrm{~b}$ & $6,7 \mathrm{~b}$ & $6,6 \mathrm{a}$ & $13,4 \mathrm{~b}$ & $4,0 \mathrm{a}$ \\
\hline CV (\%) & 6,12 & 6,41 & 25,17 & 35,69 & 6,69 & 9,55 & 5,48 & 6,08 \\
\hline D.M.S. & 5,80 & 5,95 & 4,60 & 2,24 & 0,54 & 0,59 & 0,75 & 0,29 \\
\hline
\end{tabular}

Médias seguidas pela mesma letra na coluna não diferem entre si pelo teste de Scott-Knott a 1\% de probabilidade. CV: coeficiente de variação; D.M.S.: desvio médio significativo.

Para o comprimento da parte aérea de plântulas, os tratamentos com A. blanchetti nas concentrações de $10\left(\mathrm{~T}_{3}\right)$ e $1000\left(\mathrm{~T}_{6}\right)$ ppm e $M$. charantia a $500\left(\mathrm{~T}_{9}\right)$ ppm promoveram maiores resultados em relação aos demais, embora sem diferir da testemunha $\left(\mathrm{T}_{1}\right)$. Já para o comprimento da raiz não houve diferença significativa entre os tratamentos (Tabela 7).

Em relação ao IVG, observou-se que os tratamentos com o extrato de A. blanchetti em todas as concentrações testadas e $M$. charantia a $1000\left(\mathrm{~T}_{10}\right)$ ppm proporcionaram maiores índices de velocidade em relação aos demais, diferindo significativamente da testemunha $\left(T_{1}\right)$ (Tabela 7).

$\mathrm{Na}$ tabela 8 estão contidos os resultados da qualidade fisiológica de sementes de $C$. ferrea coletadas no município de Remígio (Lote 4) e tratadas com extratos de Allamanda blanchetti e Momordica charantia.

Os tratamentos com A. blanchetti a $1000 \mathrm{ppm}\left(\mathrm{T}_{6}\right)$ e M. charantia nas concentrações de $100\left(\mathrm{~T}_{8}\right)$, $500\left(\mathrm{~T}_{9}\right)$ e $1000\left(\mathrm{~T}_{10}\right)$ ppm promoveram maiores percentuais de germinação em relação aos demais, embora sem diferir significativamente do tratamento com fungicida $\left(\mathrm{T}_{2}\right)$ e da testemunha $\left(\mathrm{T}_{1}\right)$. As demais concentrações do extrato de $A$. blanchetti $(10,100$ e 500 ppm) afetaram negativamente o percentual de germinação, promovendo resultados inferiores em relação à testemunha $\left(T_{1}\right)$ (Tabela 8).

Em relação ao percentual de germinação na primeira contagem, observou-se que os resultados assemelharam-se aos da germinação, contudo o tratamento com M. charantia a $100\left(\mathrm{~T}_{8}\right)$ ppm diferiu da testemunha $\left(T_{1}\right)$, apresentando germinação inferior (Tabela 8).

Quanto ao percentual de sementes mortas, os tratamentos com o extrato de A. blanchetti a $1000\left(\mathrm{~T}_{6}\right)$ ppm e M. charantia a $500\left(\mathrm{~T}_{9}\right)$ e $1000\left(\mathrm{~T}_{10}\right)$ ppm apresentaram menores índices, no entanto não diferiram do tratamento com fungicida $\left(\mathrm{T}_{2}\right)$ e da testemunha $\left(\mathrm{T}_{1}\right)$, enquanto que altos percentuais foram registrados com o extrato de $A$. blanchetti nas concentrações de $10\left(\mathrm{~T}_{3}\right), 100\left(\mathrm{~T}_{4}\right)$ e $500\left(\mathrm{~T}_{6}\right)$ ppm, superando a testemunha $\left(\mathrm{T}_{1}\right)$ (Tabela 8$)$.

Os extratos de A. blanchetti a $500\left(\mathrm{~T}_{5}\right)$ e $1000\left(\mathrm{~T}_{6}\right)$ ppm e $M$. charantia a $100\left(\mathrm{~T}_{8}\right)$ e $1000\left(\mathrm{~T}_{10}\right)$ ppm proporcionaram maiores resultados de comprimento da parte aérea de plântulas em relação aos demais, não diferindo da testemunha $\left(T_{1}\right)$. Em relação ao comprimento de plântulas, os tratamentos com extrato de A. blanchetti a $500\left(\mathrm{~T}_{5}\right)$ ppm e $M$. charantia nas concentrações de $100\left(\mathrm{~T}_{8}\right)$, $500\left(\mathrm{~T}_{9}\right)$ e $1000\left(\mathrm{~T}_{10}\right)$ ppm promoveram resultados superiores em comparação aos demais, embora sem diferir da testemunha $\left(\mathrm{T}_{1}\right)$ (Tabela 8$)$.

Para o IVG, os tratamentos com o extrato de A. blanchetti a $1000\left(\mathrm{~T}_{6}\right)$ ppm e M. charantia nas concentrações de $100\left(\mathrm{~T}_{8}\right), 500\left(\mathrm{~T}_{9}\right)$ e $1000\left(\mathrm{~T}_{10}\right)$ ppm resultaram em maiores índices de velocidade em relação 
aos demais, não diferindo dos tratamentos com fungicida $\left(T_{2}\right)$ e da testemunha $\left(T_{1}\right)$, evidenciando que esses tratamentos não influenciam na velocidade de germinação de sementes $C$. ferrea coletadas em Remígio. A velocidade de germinação foi reduzida significativamente nos tratamentos com o extrato de A. blanchetti a $10\left(\mathrm{~T}_{3}\right), 100\left(\mathrm{~T}_{4}\right)$ e $500\left(\mathrm{~T}_{6}\right)$ ppm, apresentando índices inferiores ao da testemunha $\left(\mathrm{T}_{1}\right)$ (Tabela 8).

Tabela 8. Valores médios de germinação $(\mathrm{G})$, primeira contagem $(\mathrm{PC})$, sementes mortas $(\mathrm{SM})$ e duras (SD), comprimentos da parte aérea (CPA), raiz (CPR), plântula (CPL) e índice de velocidade de germinação (IVG), em sementes de Caesalpinia ferrea coletadas em Remígio, PB (Lote 4) e tratadas com extratos de Allamanda blanchetti e Momordica charantia.

Table 8. Average values of germination (G), first count (PC), dead seeds (SM) and hard (SD), length of shoot (CPA), root (CPR), seedling (CPL) and germination speed index (GSI) of Caesalpinia ferrea collected at Remígio, PB (Seed Lot 4) and treated with extracts of Allamanda blanchetti and Momordica charantia.

\begin{tabular}{|c|c|c|c|c|c|c|c|c|}
\hline Tratamentos & $\begin{array}{l}\mathbf{G} \\
\ldots . . . . .\end{array}$ & PC & SM & SD & $\begin{array}{l}\text { CPA } \\
. . . . . . . . . . . . \\
\end{array}$ & $\begin{array}{l}\text { CPR } \\
\mathrm{cm} . .\end{array}$ & $\begin{array}{c}\text { CPL } \\
\ldots . . . . . . . . .\end{array}$ & IVG \\
\hline $\mathrm{T}_{1}$ - Testemunha & $91,0 \mathrm{a}$ & $79,0 \mathrm{a}$ & $7,0 \mathrm{~b}$ & $2,0 \mathrm{~b}$ & $6,7 \mathrm{a}$ & $6,8 \mathrm{a}$ & $13,5 \mathrm{a}$ & $4,4 \mathrm{a}$ \\
\hline $\mathrm{T}_{2}$ - Fungicida & $87,0 \mathrm{a}$ & $77,0 \mathrm{a}$ & $9,0 \mathrm{~b}$ & $3,0 \mathrm{~b}$ & $5,5 \mathrm{~b}$ & $7,0 \mathrm{a}$ & $12,6 \mathrm{~b}$ & $4,2 \mathrm{a}$ \\
\hline $\mathrm{T}_{3}-\mathrm{EAb} 10 \mathrm{ppm}$ & $79,0 \mathrm{~b}$ & $71,0 \mathrm{~b}$ & $17,0 \mathrm{a}$ & $4,0 \mathrm{~b}$ & $6,0 \mathrm{~b}$ & $6,2 \mathrm{~b}$ & $12,2 \mathrm{~b}$ & $3,8 \mathrm{~b}$ \\
\hline $\mathrm{T}_{4}-\mathrm{EAb} 100 \mathrm{ppm}$ & $71,0 \mathrm{~b}$ & $63,0 \mathrm{~b}$ & $18,0 \mathrm{a}$ & $11,0 \mathrm{a}$ & $6,9 \mathrm{a}$ & $5,2 \mathrm{c}$ & $12,1 \mathrm{~b}$ & $3,4 \mathrm{~b}$ \\
\hline $\mathrm{T}_{5}-\mathrm{EAb} 500 \mathrm{ppm}$ & $78,0 \mathrm{~b}$ & $70,0 \mathrm{~b}$ & $13,0 \mathrm{a}$ & $9,0 \mathrm{a}$ & $6,4 \mathrm{a}$ & $7,2 \mathrm{a}$ & $13,7 \mathrm{a}$ & $3,8 \mathrm{~b}$ \\
\hline $\mathrm{T}_{6}-\mathrm{EAb} 1000 \mathrm{ppm}$ & $84,0 \mathrm{a}$ & $78,0 \mathrm{a}$ & $9,0 \mathrm{~b}$ & $7,0 \mathrm{a}$ & $5,4 \mathrm{~b}$ & $6,9 \mathrm{a}$ & $12,3 \mathrm{~b}$ & $4,1 \mathrm{a}$ \\
\hline $\mathrm{T}_{7}-\mathrm{EMc} 10 \mathrm{ppm}$ & $75,0 \mathrm{~b}$ & $67,0 \mathrm{~b}$ & $17,0 \mathrm{a}$ & $8,0 \mathrm{a}$ & $5,4 \mathrm{~b}$ & $7,4 \mathrm{a}$ & $12,8 \mathrm{~b}$ & $3,6 \mathrm{~b}$ \\
\hline $\mathrm{T}_{8}-\mathrm{EMc} 100 \mathrm{ppm}$ & $83,0 \mathrm{a}$ & $71,0 \mathrm{~b}$ & $14,0 \mathrm{a}$ & $3,0 \mathrm{~b}$ & $6,3 \mathrm{a}$ & $6,9 \mathrm{a}$ & $13,2 \mathrm{a}$ & $4,0 \mathrm{a}$ \\
\hline $\mathrm{T}_{9}-\mathrm{EMc} 500 \mathrm{ppm}$ & $87,0 \mathrm{a}$ & $75,0 \mathrm{a}$ & $10,0 \mathrm{~b}$ & $3,0 \mathrm{~b}$ & $5,9 \mathrm{~b}$ & $7,1 \mathrm{a}$ & $13,1 \mathrm{a}$ & $4,2 \mathrm{a}$ \\
\hline $\mathrm{T}_{10}-\mathrm{EMc} 1000 \mathrm{ppm}$ & $94,0 \mathrm{a}$ & $82,0 \mathrm{a}$ & $4,0 \mathrm{~b}$ & $2,0 \mathrm{~b}$ & $6,2 \mathrm{a}$ & $7,0 \mathrm{a}$ & $13,2 \mathrm{a}$ & $4,5 \mathrm{a}$ \\
\hline $\mathrm{CV}(\%)$ & 9,29 & 9,77 & 24,48 & 29,52 & 7,39 & 7,14 & 4,59 & 9,30 \\
\hline D.M.S & 8,10 & 7,09 & 5,85 & 3,70 & 0,50 & 0,51 & 0,60 & 0,38 \\
\hline
\end{tabular}

Médias seguidas pela mesma letra na coluna não diferem entre si pelo teste de Scott-Knott a 1\% de probabilidade. CV: coeficiente de variação; D.M.S.: desvio médio significativo.

\section{DISCUSSÃO}

Análise sanitária das sementes de Caesalpinia ferrea

A análise sanitária permitiu verificar micoflora semelhante associada às sementes de Caesalpinia ferrea coletadas em diferentes municípios do estado da Paraíba, com efeitos significativos dos extratos vegetais avaliados sobre a incidência fúngica.

Os micro-organismos detectados no lote 2 (Bananeiras) são considerados de armazenamento, pois a interação de sementes com esses fungos pode aumentar consideravelmente a velocidade de deterioração das mesmas (MARCOS FILHO, 2005). Fungos como Penicillium sp. e Aspergillus sp., por exemplo, desenvolvem-se rapidamente, levando à redução da viabilidade das sementes, como observado em amendoim-bravo (Pterogyne nitens Tul.) (NASCIMENTO et al., 2006). Silva (2009), utilizando extrato de alho (Allium sativum L.) no controle de A. niger em sementes de Caesalpinia ferrea, obtiveram resultados satisfatórios, reduzindo a incidência desse fungo em até $70 \%$.

A avaliação da qualidade sanitária das sementes com o emprego de extratos vegetais tem sido analisada por diversos autores, como Silva et al. (2009), Medeiros et al. (2011) e Medeiros et al. (2013), que demonstraram que os extratos, além de proporcionarem uma redução na micoflora, promovem aumento do poder germinativo das sementes.

As maiores concentrações (500 e 1000 ppm) dos extratos de Momordica charantia e Allamanda blanchetti apresentaram resultados promissores na redução da incidência de fungos em relação às sementes não tratadas (testemunha). O tratamento alternativo de sementes é uma prática que pode ser utilizada para a eliminação de fitopatógenos associados a sementes florestais, tendo como objetivo obter uma muda com boa qualidade sanitária e silvicultural (SANTOS et al., 2011).

No entanto, o extrato de Momordica charantia nas maiores concentrações (500 e 1000 ppm) mostrou-se mais eficiente no manejo de todos os fungos detectados na avaliação sanitária dos lotes de sementes, promovendo reduções significativas na frequência desses fitopatógenos. Assim, sugerimos utilizações desse extrato na redução da micoflora associada às sementes de Caesalpinia ferrea, visto que

FLORESTA, Curitiba, PR, v. 45, n. 1, p. 163 - 174, jan. / mar. 2015.

Medeiros, J. G. F. de; Araújo Neto, A. C.; Nascimento, L. C. do

ISSN eletrônico 1982-4688 / ISSN impresso 0015-3826

171

DOI: $10.5380 /$ rf.v45i1.34074 
a utilização de produtos naturais em substituição aos agroquímicos gera ganhos ambientais importantes, além de proporcionar custos reduzidos aos produtores de mudas de espécies florestais.

A atividade antimicrobiana de macerado de tecido de Momordica charantia foi observada, em condições in vitro, sobre Bacillus subtilis, Bacillus cereus, Escherichia coli, Proteus vulgaris, Salmonella sp., Staphylococcus aureus, Saccharomyces cerevisiae, Rhodotorula glutinis, Candida sp., Rhizopus sp., Mucorra cemosus, Penicillium sp., Aspergillus niger, Aspergillus flavus, Aspergillus oryzae e Trichoderma sp. (HE, 1998). Já Torres et al. (2002) comprovaram que no extrato de uma ou mais partes da planta de Momordica charantia (sementes, folhas, haste, raízes ou frutos) são encontradas substâncias bioativas, como alcaloides, flavonoides, saponinas, glicosídeos, açúcares redutores, resinas, constituintes fenólicos, óleo fixado e ácidos livres, justificando sua atividade antifúngica e antibacteriana.

A atividade antifúngica de extrato aquoso de melão-de-são-caetano (Momordica charantia) inibiu em mais de $50 \%$ o crescimento micelial de Colletotrichum gloeosporioides isolado de fruto de mamoeiro (CELOTO et al., 2008). Bacchi et al. (2004) verificaram a atividade antifúngica do extrato aquoso de Momordica charantia, ao inibir em 35\% o crescimento micelial de Cercospora calendulae a $10000 \mu \mathrm{g} \cdot \mathrm{mL}^{-1}$ em calêndula (Calendula officinalis L.).

O extrato de melão-de-são-caetano também foi eficiente no controle de fungos em sementes de Manihot glaziovii Muell., porém apresentando variações na redução da incidência entre os diferentes gêneros - Rhizopus sp., Sphaerotheca sp., Aspergillus flavus, Chaetomium globosum e Penicillium sp. (MARTINS et al., 2009). Sendo assim, a exploração da atividade biológica dos compostos secundários presentes em extratos de plantas medicinais como o melão-de-são-caetano pode representar uma forma potencial de controle alternativo de fitopatógenos (SCHWAN-ESTRADA; STANGARLIN, 2005).

\section{Análise da qualidade fisiológica das sementes de Caesalpinia ferrea}

O emprego das maiores concentrações (500 e 1000 ppm) dos extratos de Allamanda blanchetti e Momordica charantia promoveu ganhos significativos na qualidade fisiológica das sementes de Caesalpinia ferrea dos lotes 2 (Bananeiras) e 3 (Conde). Nesses lotes, a incidência fúngica afetou negativamente a qualidade das sementes não tratadas (testemunha), fato também observado por Cherobini (2006), que, em estudos com espécies florestais nativas, verificou que a presença de patógenos nas sementes pode interferir na sua qualidade fisiológica. Dessa forma, podemos associar os prejuízos na qualidade fisiológica à elevada incidência de patógenos nas sementes. Esses resultados corroboram os observados em sementes de zínia (Zinnia elegans L.), em que a testemunha apresentou germinação inferior às sementes tratadas com extratos de alho (Allium sativum) e hortelã (Mentha piperita) (GIRARDI et al., 2009).

De modo semelhante, Medeiros et al. (2013), utilizando os extratos de Allamanda blanchetti e Momordica charantia como controle alternativo de patógenos em sementes de amedoim-bravo (Pterogyne nitens Tul.), obtiveram um efeito direto na redução da micoflora e no aumento da germinação das sementes.

Os estudos de Mata et al. (2009) mostraram que o emprego de óleos essenciais e extratos de plantas medicinais no tratamento prévio de sementes promoveu redução da micoflora e aumento do poder germinativo das sementes de mandacaru (Cereus jamacaru DC.). A importância da utilização de produtos naturais no tratamento de sementes é ressaltada por Von Pinho et al. (1995), que enfatizam o emprego de plantas com comprovadas atividades antimicrobianas na forma de extratos e óleos essenciais. Parisi et al. (2011) afirmam que sementes predispostas à ação de micro-organismos, quando tratadas, reduzem a capacidade de sobrevivência dos fitopatógenos e potencializam e longevidade das sementes, seu poder germinativo e o vigor das futuras plantas.

Nos lotes 1 e 4, colhidos nos municípios paraibanos de Areia e Remígio, respectivamente, não houve influência dos tratamentos com o extrato de Momordica charantia (10, 100, 500 e 1000 ppm) na qualidade fisiológica das sementes de $C$. ferrea. Já o extrato de $A$. blanchetti nas concentrações testadas afetou negativamente o percentual e a velocidade de germinação em relação à testemunha, possivelmente em decorrência de algum efeito alelopático inibitório da germinação das sementes dessa espécie. Efeito semelhante também foi observado por Scherer et al. (2005), ao verificarem que extratos aquosos de folhas (100\%) e frutos (60, 80 e 100\%) de leucena (Leucaena leucocephala Wit.) reduzem significativamente o percentual e a velocidade média de germinação de sementes de canafístula (Peltophorum dubium Spreng). Piña-Rodrigues e Lopes (2001) também observaram efeito alelopático do extrato de folhas verdes de sabiá (Mimosa caesalpiniaefolia Benth.), com a redução da velocidade ou inibição da germinação das sementes de ipê-amarelo (Tabebuia alba (Cham.) Sandw.). Tal resultado 
evidencia que a qualidade sanitária e fisiológica de lotes de sementes de $C$. ferrea tratadas com extratos vegetais é bastante variável em função do seu local de coleta.

Vale ressaltar que na avaliação final dos testes de germinação não foram verificadas alterações morfológicas e/ou sinais de fitotoxidez nas plântulas, provocadas pela utilização dos extratos vegetais, demonstrando que a aplicação desses produtos naturais, nas concentrações testadas, não afeta a estrutura e o estabelecimento das plântulas de $C$. ferrea.

Apesar de a obtenção dos extratos de A. blanchetti e M. charantia demandar certa tecnologia, é um processo não oneroso, podendo ser acessível aos produtores de mudas de C. ferrea. Além disso, são espécies que ocorrem naturalmente nos mais diversos ambientes, não havendo problemas com escassez de matéria-prima. No entanto, estudos futuros são necessários, com o objetivo de isolar e quantificar as substâncias bioativas desses extratos, bem como testar a eficiência de concentrações intermediárias, a fim de serem utilizados em menores quantidades.

\section{CONCLUSÕES}

- Nas sementes de Caesalpinia ferrea, foram identificados os fungos Aspergillus flavus, Aspergillus niger, Cladosporium sp., Rhizopus stolonifer, Penicillium sp. e Nigrospora sp.

- Os extratos de Allamanda blanchetti e Momordica charantia nas concentrações de 500 e 1000 ppm reduziram a incidência de fungos fitopatogênicos em sementes de $C$. ferrea.

- Os extratos de Allamanda blanchetti e Momordica charantia nas maiores concentrações (500 e $1000 \mathrm{ppm}$ ) promoveram o aumento no percentual e na velocidade de germinação, bem como no comprimento das plântulas de C. ferrea.

\section{REFERÊNCIAS}

BACCHI, L. M. A.; NASCIMENTO, J. M.; GAVASSONI, W. L.; VIEIRA, M. C. Inibição in vitro de Cercospora calendulae por extratos de calêndula e melão-de-são-caetano. Fitopatologia Brasileira, Brasília, v. 29, p. 233, 2004.

BRASIL, Ministério da Agricultura, Pecuária e Abastecimento. Regras para Análise de Sementes. Secretária de Defesa Agropecuária. Brasília: MAPA/ACS, 2009. 399 p.

CELOTO, M. I. B.; PAPA, M. F. S.; SACRAMENTO, L. V. S.; CELOTO, F. J. Atividade antifúngica de extratos de plantas em Colletotrichum gloeosporioides. Acta Scientiarum, Maringá, v. 30, n. 1, p. 1 - 5, 2008.

CHEROBINI, E. A. I. Avaliação da qualidade de sementes e mudas de espécies florestais nativas. 115 f. Dissertação (Mestrado em Engenharia Florestal) - Universidade Federal de Santa Maria, RS, 2006.

GIRARDI, L. B.; LAZAROTTO, M.; MÜLLER, J.; DURIGON, M. R.; MUNIZ, M. F. B.; BLUME, E. Extratos vegetais na qualidade fisiológica e sanitária de sementes de zínia (Zinnia elegans). Revista Brasileira de Agroecologia, Porto Alegre, v. 4, n. 2, p. 897 - 900, 2009.

HE, Y. B. Antimicrobial activity of Momordica charantia. Food Science, v. 19, n. 3, p. 34 - 36, 1998.

LAZAROTTO, M.; MUNIZ, M. F. B.; BELTRAME, R.; SANTOS, A. F.; MACIEL, C. G.; LONGHI, S. J. Sanidade, transmissão via semente e patogenicidade de fungos em sementes de Cedrela fissilis procedentes da região Sul do Brasil. Ciência Florestal, Santa Maria, v. 22, n. 3, p. 1 - 11, 2012.

LIMA, J. D.; ALMEIDA, C. C.; DANTAS, V. A. V.; SILVA, B. M.; MORAES, W. S. Efeito da temperatura e do substrato na germinação de sementes de Caesalpinia ferrea Mart. ex Tul. (Leguminosae, Caesalpinoideae). Revista Árvore, Viçosa, v. 30, n. 4, p. 513 - 518, 2006.

LINS, S. R. O.; OLIVEIRA, S. M. A.; ALEXANDRE, E. R.; SANTOS, A. M. G.; OLIVEIRA, T. A. S. Controle alternativo da podridão peduncular em manga. Summa Phytopathologica, Campinas, v. 37, n. 3, p. $121-126,2011$.

LORENZI, H.; MATOS, F. J. A. Plantas medicinais no Brasil: nativas e exóticas. 2. ed. Nova Odessa: Instituto Plantarum, 2008. $512 \mathrm{p}$.

MARCOS FILHO, J. Fisiologia de sementes de plantas cultivadas. Piracicaba: FEALQ, 2005. 495 p.

MARTHUR, S. B.; KONGSDAL, O. Common laboratory seed health testing methods for detecting fungi. Basserdorf: International Seed Testing Association, 2003. 425 p. 
MARTINS, M. T. C. S.; NASCIMENTO, L. C.; ARAÚJO, E. R.; RÊGO E. R.; FELIX, L. P. Atividade antifúngica de extrato de melão-de-são-caetano em sementes de maniçoba. Horticultura Brasileira, Brasília, v. 27, S1246-S1253, 2009.

MATA, M. F.; ARAÚJO, E.; NASCIMENTO, L. C.; SOUZA, A. E. F.; VIANA, S. Incidência e controle alternativo de patógenos em sementes de mandacaru (Cereus jamacaru DC., Cactaceae). Revista Brasileira de Biociências, Porto Alegre, v. 7, n. 4, p. 327 - 334, 2009.

MEDEIROS, J. G. F.; ARAÚJO NETO, A. C.; MEDEIROS, D. S.; NASCIMENTO, L. C.; ALVES, E. U. Extratos vegetais no controle de patógenos em sementes de Pterogyne nitens Tul. Floresta e Ambiente, Seropédica, v. 20, n. 3, p. 384 - 390, 2013.

MEDEIROS, J. G. F.; LEITE, R. P.; NASCIMENTO, L. C. Extratos vegetais e seus efeitos na sanidade e fisiologia de sementes de flamboyant-mirim (Caesalpinia pulcherrima L.). In: SEABRA, G.; MENDONÇA, I. (Eds.). Educação ambiental: Responsabilidade para a conservação da sociobiodiversidade. João Pessoa: Editora Universitária, 2011. p. 373 - 377.

NASCIMENTO, W. M. O.; CRUZ, E. D.; MORAES, M. H. D.; MENTEN, J. O. M. Qualidade sanitária e germinação de sementes de Pterogyne nitens Tull. (Leguminosae - Caesalpinioideae). Revista Brasileira de Sementes, Brasília, v. 28, n. 1, p.149 - 153, 2006.

PARISI, J. J. D.; SANTOS, A. F.; MENTEN, J. O. M. Tratamento de sementes florestais. In: Patologia de Sementes Florestais. 1. ed. Colombo: Embrapa Florestas, p. 105 - 114. 2011.

PIÑA-RODRIGUES, F. C. M.; LOPES, B. M. Potencial alelopático de Mimosa caesalpinaefolia Benth. sobre sementes de Tabebuia alba (Cham.) Sandw. Floresta e Ambiente, Seropédica, v. 8, n. 1, p. 130 - 136, 2001.

SANTOS, A. F.; PARISI, J. J. D; MENTEM, J. O. M. (Ed.). Patologia de sementes florestais. Colombo: Embrapa Florestas, 2011. 236 p.

SAS INSTITUTE. SAS/STAT software: changes and enhancements, release 6.07. Cary: Statistical Analysis System Institute, 1992. Chapter 16: The MIXED procedure. (SAS. Technical Report P-229).

SCHERER, L. M.; ZUCARELI, V.; ZUCARELI, C. A.; FORTES, A. M. T. Efeito alelopático do extrato aquoso de folha e de fruto de leucena (Leucaena leucocephala Wit.) sobre a germinação e crescimento de raiz da canafístula (Peltophorum dubium Spreng). Semina: Ciências Biológicas e Saúde, Londrina, v. 26, n. 2, p. 161 - 166, 2005.

SCHWAN-ESTRADA, K. R. F.; STANGARLIN, J. R. Extratos e óleos essenciais de plantas medicinais na indução de resistência. In: CAVALCANTI, L. S.; DI PIERO, R. M.; CIA, P.; PASCHOLATI, S. F.; RESENDE, M. L. V.; ROMEIRO, R. S. (Eds.). Indução de resistência em plantas a patógenos e insetos. Piracicaba: FEALQ, 2005. p. 125 - 138.

SILVA, J. A.; PEGADO, C. M. A.; RIBEIRO, V. V. Efeito de extratos vegetais no controle de Fusarium oxysporum f. sp. tracheiphilum em sementes de caupi. Ciência e Agrotecnologia, Lavras, v. 33, n. 2, p. $611-616,2009$.

SILVA, V. V. M. Extrato de alho na redução da incidência de Aspergillus niger em sementes de Caesalpinia ferrea Mart. 23 f. Monografia (Graduação em Engenharia Florestal) - Centro de Saúde e Tecnologia Rural, Universidade Federal de Campina Grande, Patos, 2009.

TORRES, L. D.; ORTINERO, C. V.; MONSERATE, J. J. Crop wastes as potential sources of natural medicine/cosmetic products, pesticides/insecticides, and paper products. PCARRD-Highlights-2001, p. 424 - 444, 2002.

VENTUROSO, L. R.; BACCHI, L. M. A.; GAVASSONI, W. L. Atividade antifúngica de extratos vegetais sobre o desenvolvimento de fitopatógenos. Summa Phytopathologica, Campinas, v. 37, n. 1, p. $18-23,2011$.

VON PINHO, E. V. R.; SILVEIRA, J. F.; VIEIRA, M. G. G. C.; FRAGA, A. C. Influência do tamanho e do tratamento de sementes de milho na preservação da qualidade durante o armazenamento e posterior comportamento no campo. Ciência e Prática, Bebedouro, v. 19, n. 1, p. 20 - 25, 1995.

ZAUZA, E. A. V.; ALFENAS, A. C.; MAFIA, R. G. Esterilização, preparo de meios de cultura e fatores associados ao cultivo de fitopatógenos. In: ALFENAS, A. C.; MAFIA, R. G. (Eds.). Métodos em fitopatologia. Viçosa: UFV, 2007. p. 23 - 51. 